\title{
Influence of sodium fumarate addition on rumen fermentation in vitro
}

\author{
S. López*†, C. Valdés†, C. J. Newbold and R. J. Wallace \\ Rowett Research Institute, Bucksburn, Aberdeen AB21 9SB, UK
}

(Received 6 August 1997 - Revised 15 July 1998 - Accepted 28 September 1998)

\begin{abstract}
The influence of sodium fumarate on rumen fermentation was investigated in vitro using batch and semi-continuous cultures of mixed rumen micro-organisms taken from three sheep receiving a basal diet of hay, barley, molasses, fish meal and a mineral-vitamin supplement (500, 299.5, 100,91 and $9.5 \mathrm{~g} / \mathrm{kg}$ DM respectively). Batch cultures consisted of $10 \mathrm{ml}$ strained rumen fluid in $40 \mathrm{ml}$ anaerobic buffer containing $200 \mathrm{mg}$ of the same feed given to the sheep. Sodium fumarate was added to achieve a final concentration of 0,5 or $10 \mathrm{mmol} / \mathrm{l}$, as a result of the addition of 0 , 250 or $500 \mu \mathrm{mol}$, equivalent to 0,200 and $400 \mathrm{~g} / \mathrm{kg}$ feed. $\mathrm{CH}_{4}$ production at $24 \mathrm{~h}(360 \mu \mathrm{mol}$ in the control cultures) fell $(P<0.05)$ by 18 and $22 \mu \mathrm{mol}$ respectively (SED 7.5). Total gas production was increased by the addition of fumarate without significant accumulation of $\mathrm{H}_{2}$. Substantial increases in acetate production (92 and $194 \mu \mathrm{mol}$; SED 26.7, $P<0 \cdot 01$ ) were accompanied by increases in propionate formation (212 and $396 \mu$ mol; SED 13.0, $P<0 \cdot 001)$. Longer-term effects of fumarate supplementation on ruminal fermentation and $\mathrm{CH}_{4}$ production were investigated using the rumen simulation technique (Rusitec). Eight vessels were given $20 \mathrm{~g}$ basal diet/d, and half of them received a supplement of fumarate (disodium salt) over a period of $19 \mathrm{~d}$. The response to the daily addition of $6.25 \mathrm{mmol}$ sodium fumarate was a decrease in $\mathrm{CH}_{4}$ production of $1.2 \mathrm{mmol}$ (SED $0 \cdot 39, P<0 \cdot 05$ ), equivalent to the consumption of $4.8 \mathrm{mmol} \mathrm{H}_{2}$, and an increase in propionate production of $4.9 \mathrm{mmol}$ (from 10.4 to 15.3 (SED 1.05 ) $\mathrm{mmol} / \mathrm{d}, P<0.01$ ). The inhibition of $\mathrm{CH}_{4}$ production did not decline during the period of time that fumarate was added to the vessels. Thus, the decrease in $\mathrm{CH}_{4}$ corresponded well to the fraction of the fumarate that was converted to propionate. Fumarate had no significant $(P>0.05)$ effect on total bacterial numbers or on the number of methanogenic archaea, but numbers of cellulolytic bacteria were increased $(8.8$ v. 23.9 (SED 2.49$) \times 10^{5}$ per $\left.\mathrm{ml}, P<0.01\right)$. Fumarate also increased DM digestibility of the basal diet after $48 \mathrm{~h}$ incubation $(0.476 v .0 .508$ (SED 0.0123), $P<0.05)$. Thus, it was concluded that sodium fumarate may be a useful dietary additive for ruminants, because it diverts some $\mathrm{H}_{2}$ from $\mathrm{CH}_{4}$ production and because it is able to stimulate proliferation of cellulolytic bacteria and digestion of fibre.
\end{abstract}

\section{Rumen: Fumarate: Methane: Rusitec}

$\mathrm{CH}_{4}$ formation represents a substantial loss of energy to the ruminant animal, and it is also a significant source of greenhouse gas emissions from agriculture (Moss, 1993). Inhibition of $\mathrm{CH}_{4}$ production by ruminants would therefore have significant economical and environmental benefits (Van Nevel \& Demeyer, 1996). Many chemical compounds (mainly antimicrobial compounds) have been tested as potential feed additives for ruminants on the basis of their direct or indirect effects on $\mathrm{CH}_{4}$ production in the rumen (Moss, 1993; Van Nevel \& Demeyer, 1996). These include ionophores, halogenated $\mathrm{CH}_{4}$ analogues and unsaturated fatty acids. One possible way to decrease $\mathrm{CH}_{4}$ formation in the rumen is to promote alternative metabolic pathways to dispose of the reducing power, competing with methanogenesis for the $\mathrm{H}_{2}$ uptake. Fumaric acid is a four-C dicarboxylic acid that is an intermediate in the propionate pathway, in which it is reduced to succinate by fumarate reductase (EC 1.3.99.1). Reducing equivalents are needed in this reaction and therefore fumarate may provide an alternative electron sink for hydrogen. As hydrogen is used to reduce fumarate, there is a decline in the availability of $\mathrm{H}_{2}$ for methanogenesis in the rumen. Fumarate and other dicarboxylic acids also seem to stimulate the growth and activity of the lactic acid-utilizing rumen bacterium Selenomonas ruminantium (Nisbet \& Martin, 1990), providing an electron sink for this organism (Martin \& Park, 1996). $\mathrm{CH}_{4}$ production by

\footnotetext{
Abbreviations: Rusitec, rumen simulation technique.

* Corresponding author: Dr Secundino López at his present address, fax +34 987291 311, email DP1SLP@ISIDORO.UNILEON.ES

$\dagger$ Present address: Departamento de Producción Animal, Universidad de León, E-24071 León, Spain.
} 
mixed rumen bacteria was decreased for short periods in vitro when fumarate was added to the medium (Demeyer \& Henderickx, 1967). The objectives of the present study were to evaluate the effect of fumarate on $\mathrm{CH}_{4}$ production in short-term in vitro batch incubations and to determine the long-term effects of fumarate on ruminal fermentation in the semi-continuous rumen simulation technique (Rusitec).

\section{Materials and methods}

\section{In vitro batch fermentations}

Short-term in vitro incubations were carried out with rumen fluid withdrawn from three rumen-cannulated sheep. The sheep received $1.4 \mathrm{~kg} / \mathrm{d}$ of a mixed diet consisting of grass hay, barley, molasses, white fishmeal and a vitamin and mineral mixture $(500,299.5,100,91$ and $9.5 \mathrm{~g} / \mathrm{kg} \mathrm{DM}$ respectively) in two equal meals. Rumen fluid was withdrawn, via the cannula, $2 \mathrm{~h}$ after the morning feed and, after mixing the samples from the three sheep, it was strained through two layers of muslin and maintained at $39^{\circ}$ under $\mathrm{O}_{2}$-free $\mathrm{CO}_{2}$. Rumen fluid was anaerobically transferred $(200 \mathrm{ml} / \mathrm{l})$ to a Simplex-type buffer containing (/l): $5 \mathrm{~g}$ $\mathrm{K}_{2} \mathrm{HPO}_{4}, 4 \mathrm{~g} \mathrm{KH}_{2} \mathrm{PO}_{4}, 0.52 \mathrm{~g} \mathrm{NaCl}, 70 \mathrm{mg} \mathrm{MgSO}_{4} .7 \mathrm{H}_{2} \mathrm{O}$, $35 \mathrm{mg} \mathrm{CaCl} 2,5.9 \mathrm{~g} \mathrm{NaHCO}_{3}$ and $174 \mathrm{mg}$ cysteine hydrochloride, which had been prepared as described by Coleman (1987). After mixing, $50 \mathrm{ml}$ buffered rumen fluid was anaerobically dispensed into each of twelve $120 \mathrm{ml}$ serum bottles containing $200 \mathrm{mg}$ of the diet described earlier, previously ground to pass through a $1 \mathrm{~mm}$ mesh screen. Weighed amounts of fumarate (disodium salt; Sigma Chemical Co., Poole, Dorset, UK) were added to achieve final concentrations of 0,5 and $10 \mathrm{mmol} / \mathrm{l}$. The bottles were sealed $\left(\mathrm{CO}_{2}\right.$ atmosphere) with rubber stoppers and aluminium caps and were placed in a shaking water bath at $39^{\circ}$. After $24 \mathrm{~h}$ incubation, total gas production was measured using a $100 \mathrm{ml}$ lubricated syringe connected to a needle, which was inserted through the stoppers into the headspace. A gas sample $(1 \mathrm{ml})$ was removed from each bottle and analysed for $\mathrm{CH}_{4}$ and $\mathrm{H}_{2}$ by GLC on a $4 \mathrm{~mm} \times 3 \mathrm{~m}$ glass column packed with Porapak Q mesh 60-80 (Waters Associates Inc., Milford, MA, USA). The oven temperature was $250^{\circ}$ and the carrier gas $(\mathrm{He})$ flow rate was $30 \mathrm{ml} / \mathrm{min}$; a katherometer detector was used. Peaks were identified by comparison with gas standards of known composition. The bottles were then uncapped and the $\mathrm{pH}$ was measured using a pH electrode connected to a Russell $660 \mathrm{pH}$ meter (Russell $\mathrm{pH}$, Auchtermuchty, Fife, UK). Fermentation fluid $(4 \mathrm{ml})$ was added to $1 \mathrm{ml}$ of an acid solution containing $200 \mathrm{ml}$ orthophosphoric acid/l and $20 \mathrm{~mm}$-2-ethyl-butyric acid. Acidified samples were centrifuged $\left(27800 \mathrm{~g}, 5^{\circ}, 15 \mathrm{~min}\right)$ and volatile fatty acids were determined by GLC using ethylbutyric acid as the internal standard as described by Stewart \& Duncan (1985).

\section{Fermentation in the Rusitec}

The Rusitec was used as described by Czerkawski \& Breckenridge (1977). The nominal volume in each reaction vessel was $850 \mathrm{ml}$ and the dilution rate was set at 0.88 per d, the infused liquid being artificial saliva (McDougall, 1948) at $\mathrm{pH} 8$.4. Inocula for the fermentation vessels were obtained from a pooled sample (liquid and particulate rumen contents) from the three rumen-cannulated sheep used in the in vitro trial. On the first day of the experiment $300 \mathrm{ml}$ strained rumen fluid and $300 \mathrm{ml}$ artificial saliva were placed in each reaction vessel. Solid rumen contents $(80 \mathrm{~g})$ were weighed into a nylon bag and one of these was placed inside the food container in each vessel together with a bag of food. The food was the same forage-concentrate diet fed to the donor animals, and was provided in nylon bags, pore size $50 \mu \mathrm{m}$, which were gently agitated in the liquid phase. Two bags were present at any time and one bag was replaced each day to give a $48 \mathrm{~h}$ incubation. The bags that were removed from the vessels were placed in plastic bags, and their contents washed and squeezed with $40 \mathrm{ml}$ artificial saliva. This was done twice for each bag, and the combined washings were poured back into the reaction vessels. Fermentation vessels were flushed with anaerobicgrade $\mathrm{CO}_{2}$ before filling, after filling, and then every day during feeding (when the nylon bags with the food were changed).

Eight vessels were set up as described earlier (Czerkawski \& Breckenridge, 1977) and were supplied at the same time every day with $20 \mathrm{~g}$ of the basal diet fed to the donor animals. The duration of the experiment was $26 \mathrm{~d}$, which consisted of period 1 (days 1-19) in which four vessels received $1 \mathrm{~g}$ fumarate (disodium salt) daily, which was added to the basal diet, the remaining vessels being controls, and period 2 (days 20-26) in which no fumarate was added to any vessel. Gas samples were taken over days 8-19 and on the last $2 \mathrm{~d}$ in period 2, and analysed by GLC as described earlier, to determine $\mathrm{H}_{2}$ and $\mathrm{CH}_{4}$ concentrations.

During the last $2 \mathrm{~d}$ of each period, fermentation products were determined on samples taken from the liquid overflow, as described by Newbold et al. (1997). Fermentation acids were detected by capillary GC, using the derivatization method described by Richardson et al. (1989). $\mathrm{NH}_{3}$ was measured by the phenol-hypochlorite method of Weatherburn (1967). In liquid samples from period 2, volatile fatty acids were analysed, with no derivatization, by GLC (Stewart \& Duncan, 1985). The volume of the liquid overflow, together with the concentration of fermentation products, was used to calculate the daily output of fermentation products. $\mathrm{pH}$ was measured as described earlier in samples of fermentation fluid withdrawn from around the nylon bags at the time of feeding. The digestibility of the diet was estimated from the DM remaining in the bags after $48 \mathrm{~h}$ incubation. DM in feed samples and in incubation residues was determined by drying at $105^{\circ}$ for $48 \mathrm{~h}$.

Samples for microbial counting were taken on the last $2 \mathrm{~d}$ of the first period (days 18 and 19) of the Rusitec experiment. Protozoa in the liquid phase were enumerated microscopically in a counting chamber (Newbold et al. 1987). Hungate's methods (Hungate, 1969) were used to prepare media and to cultivate bacteria. Media were dispensed into Hungate tubes sealed with butyl rubber stoppers (Belco Glass Inc., Vineland, NJ, USA). A sample of fermentation fluid $(20 \mathrm{ml})$ taken directly from the reaction vessel and a sample of the digesta $(1 \mathrm{~g})$ remaining in the nylon bags incubated for the last $48 \mathrm{~h}$ were homogenized together, under $\mathrm{O}_{2}$-free $\mathrm{CO}_{2}$, for $1 \mathrm{~min}$ using an MSE top-bladed 
homogenizer (MSE, Crawley, Sussex, UK) at full speed. Serial 10-fold dilutions were prepared under $\mathrm{O}_{2}$-free $\mathrm{CO}_{2}$ for each sample by the anaerobic method of Bryant (1972) using an anaerobic diluent (Mann, 1968). Total viable bacteria were enumerated in roll tubes with a complex rumen fluid-sugars medium to which $20 \mathrm{~g}$ agar/l was added (Medium M2, Hobson, 1969), and these tubes were incubated for $72 \mathrm{~h}$ at $39^{\circ}$. Cellulolytic counts were done by a most-probable-number method based on the degradation of filter paper strips (Mann, 1968). Numbers of methanogenic archaea were determined by a most-probable-number technique, based on the production of $\mathrm{CH}_{4}$ in a medium containing formate, acetate and $\mathrm{H}_{2}$ (Morvan et al. 1994).

\section{Statistical analyses}

In vitro incubations were performed on $2 \mathrm{~d}$ with two replicates per d $(n 4)$. Data were analysed as a one-way ANOVA with three concentrations of fumarate $(0,5,10 \mathrm{mmol} / \mathrm{l})$. Orthogonal polynomial contrasts were performed to study linear effects (SAS Institute Inc., 1989). Comparisons between treatment means were tested by the least significant difference method. For the trial carried out in the Rusitec, reaction vessels were randomly assigned to control (untreated) and fumarate groups. Variables measured over $12 \mathrm{~d}$ (gas and $\mathrm{CH}_{4}$ production, DM digestibility) were analysed as a repeated measures ANOVA with the Greenhouse-Geisser adjustment as given by PROC GLM in the Statistical Analysis Systems program (SAS Institute Inc., 1989). Effect of fumarate addition was tested using vessel within treatment (df 6) as the error term, whereas sampling day was the within-subject effect (SAS Institute Inc., 1989) as repeated measures taken on the same experimental unit. For all the other variables, treatment effects were established by a $t$ test (Steel \& Torrie, 1980), and significance was declared at $P<0.05$ unless otherwise stated. Computations were performed using the general linear models procedure of the Statistical Analysis Systems program (SAS Institute Inc., 1989).

\section{Results}

In vitro batch incubations

The addition of fumarate significantly increased the final $\mathrm{pH}$
$(P<0.05)$ and total gas production $(P<0.01)$ during the $24 \mathrm{~h}$ incubation (Table 1). The $\mathrm{CH}_{4}$ concentration in the gas produced was significantly $(P<0 \cdot 05)$ decreased by the addition of fumarate $\left(256,229\right.$ and $219 \mathrm{mmol} \mathrm{CH}_{4} / \mathrm{mol}$ gas for 0,5 and $10 \mathrm{~mm}$-fumarate respectively), thus resulting in a significant $(P<0.05)$ fall in $\mathrm{CH}_{4}$ production as the dose of fumarate added to the medium increased. However, 250 and $500 \mu \mathrm{mol}$ fumarate caused decreases of only 18 and $22 \mu \mathrm{mol}$ in $\mathrm{CH}_{4}$ production $\left(5.3\right.$ and $6.4 \%$ of the $\mathrm{CH}_{4}$ produced in the control cultures).

Acetate production was increased $(P<0.01)$ by about $100 \mu \mathrm{mol}$ for each $250 \mu \mathrm{mol}$ fumarate addition, whereas fumarate addition had no significant $(P>0 \cdot 10)$ effect on butyrate production. Propionate production increased $(P<$ $0 \cdot 001$ ) by about $200 \mu \mathrm{mol}$ for each $250 \mu \mathrm{mol}$ fumarate added.

\section{Effects of fumarate on fermentation in the Rusitec}

Total gas production was unaffected $(P>0.05)$ by fumarate during period 1 , whereas $\mathrm{CH}_{4}$ production measured over days 8-19 of the experiment was significantly decreased $(P<0.05)$ by fumarate addition (Table 2$)$, but only by $1.2 \mathrm{mmol}(17 \%)$ for an addition of $6.25 \mathrm{mmol}$ sodium fumarate. This effect was consistent over the time that fumarate was added to the vessels, with no significant $(P=0 \cdot 361)$ differences between sampling days and no significant interaction $(P=0.669)$ between treatment and sampling day (both $P$ values are those adjusted for a Greenhouse-Geisser epsilon of 0.2942). The inhibition in $\mathrm{CH}_{4}$ production by adding fumarate did not result $(P>$ 0.05 ) in the accumulation of $\mathrm{H}_{2}$ gas. Adding fumarate also increased the digestion of the basal diet in the fermenter, since the DM digestibility was $6.3 \%$ higher when fumarate was added to the diet compared with the control cultures. The only significant effect of fumarate on microbial numbers was that cellulolytic bacteria were increased $(P<$ 0.01). Methanogenic archaea were unaffected. Fumarate had no significant $(P>0.05)$ effect on the $\mathrm{pH}$ in the fermentation vessels (Table 3 ). Fumarate addition resulted in a significant $(P<0.01)$ increase in propionate production, but did not affect the production of formate, lactate, butyrate and other volatile fatty acids (Table 3). An increase of $4.9 \mathrm{mmol}$ propionic acid occurred in response to the

Table 1. Influence of sodium fumarate on $24 \mathrm{~h}$ fermentation by mixed rumen micro-organisms in in vitro batch cultures*

(Mean values for four fermentations with the standard error of difference between means)

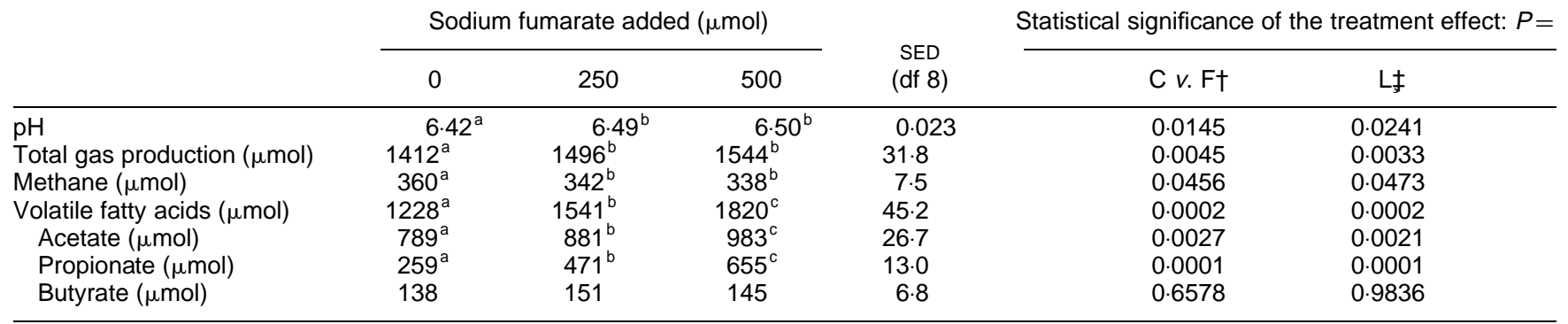

\footnotetext{
a,b,c Mean values within a row not sharing a common superscript letter were significantly different, $P<0.05$.

${ }^{*}$ For details of procedures, see pp. 60-61.

† Orthogonal contrasts, C v. F: comparison between control and fumarate treatment.

$\ddagger$ Orthogonal polynomials, linear $(L)$ effects of fumarate dose.
} 
Table 2. Influence of sodium fumarate addition $(6.25 \mathrm{mmol} / \mathrm{d})^{*}$ on the output of methane and hydrogen from, and the digestion of, dry matter and on microbial numbers in the rumen simulation technique (Rusitec) $\dagger$

(Mean values for four vessels, with the standard error of difference between means)

\begin{tabular}{lcccc}
\hline & Control & Fumarate & SED $(6 \mathrm{df})$ & Statistical significance of the difference, $P=$ \\
\hline Gas production $(\mathrm{mmol} / \mathrm{d}) \ddagger$ & 58.0 & $54 \cdot 2$ & 3.51 & 0.3196 \\
Hydrogen $(\mathrm{mmol} / \mathrm{d}) \ddagger$ & 0.31 & 0.22 & 0.116 & 0.4675 \\
Methane $(\mathrm{mmol} / \mathrm{d}) \ddagger$ & $7 \cdot 0$ & 5.7 & 0.39 & 0.0167 \\
Digestion of $\mathrm{DM}(\mathrm{g} / \mathrm{kg})$ after $48 \mathrm{~h}$ incubation $\ddagger$ & 476 & 508 & 12.3 & 0.0410 \\
Total bacteria $\left(\times 10^{8} / \mathrm{ml}\right) \S$ & $5 \cdot 4$ & 4.7 & 0.69 & 0.3495 \\
Methanogenic archaea $\left(\times 10^{6} / \mathrm{ml}\right) \S$ & 14.2 & 14.9 & 4.21 & 0.8734 \\
Cellulolytic bacteria $\left(\times 10^{5} / \mathrm{ml}\right) \S$ & 8.8 & 23.9 & 2.49 & 0.0010 \\
Protozoa $\left(\times 10^{3} / \mathrm{ml}\right) \S$ & 4.4 & 3.8 & 0.68 & 0.4115 \\
\hline
\end{tabular}

* Sodium fumarate was added to Rusitec vessels for $19 \mathrm{~d}$

† For details of procedures, see pp. 60-61.

$\ddagger$ Each value is the mean of the observations taken during the last $12 \mathrm{~d}$ of fumarate addition

$\S$ Each value is the mean of the observations taken during the last $2 \mathrm{~d}$ of fumarate addition.

addition of $6.25 \mathrm{mmol}$ sodium fumarate. Fumarate also caused the accumulation of succinate in the culture, whereas no succinate was detected in the effluent of control vessels. $\mathrm{NH}_{3}$ production was unaffected by the addition of fumarate. When fumarate treatment was stopped the differences in DM digestibility, $\mathrm{CH}_{4}$ and volatile fatty acid production disappeared (Table 4).

\section{Discussion}

Recently, some dicarboxylic acids, such as aspartate, malate and fumarate, have been tested as feed additives for ruminants (Callaway \& Martin, 1996; Martin \& Park, 1996). The results presented in the present paper describe the short- and long-term effects of one of these dicarboxylic acids, sodium fumarate, on rumen fermentation.

The $6 \%$ decrease in $\mathrm{CH}_{4}$ formation found when fumarate was added to batch cultures in the present study is fairly consistent with the low response found by Callaway \& Martin (1996), but very different to the value of $60 \%$ found by Demeyer \& Henderickx (1967). Since many factors can influence $\mathrm{CH}_{4}$ production, responses may

Table 3. Influence of sodium fumarate $(6.25 \mathrm{mmol} / \mathrm{d}){ }^{\star}$ on $24 \mathrm{~h}$ fermentation (output of end-products, $\mathrm{mmol} / \mathrm{d}$ ) in the rumen simulation technique (Rusitec) $\dagger$

(Mean values for four vessels, with the standard error of difference between means)

\begin{tabular}{lcccc}
\hline & Control & Fumarate & SED $(6 \mathrm{df})$ & Statistical significance of the difference, $P=$ \\
\hline pH & 6.74 & 6.77 & 0.048 & 0.5768 \\
Formate & 0.49 & 0.43 & 0.056 & 0.3586 \\
Acetate & 26.2 & 29.7 & 2.30 & 0.1818 \\
Propionate & 10.4 & 15.3 & 1.05 & 0.0033 \\
Butyrate & 8.6 & 8.7 & 0.86 & 0.8776 \\
Valerate & 3.3 & 4.1 & 0.33 & 0.0572 \\
Isobutyrate & 0.29 & 0.31 & 0.033 & 0.5587 \\
Isovalerate & 0.16 & 0.20 & 0.038 & 0.3216 \\
Succinate & 0.00 & 0.47 & 0.053 & 0.0001 \\
Lactate & 0.21 & 0.08 & 0.130 & 0.3626 \\
Ammonia & 2.77 & 2.75 & 0.246 & 0.9378
\end{tabular}

* Sodium fumarate was added to Rusitec vessels for $19 \mathrm{~d}$, and each value is the mean of the observations taken during the last $2 \mathrm{~d}$ of that period.

† For details of procedures, see pp. 60-61.

Table 4. Fermentation characteristics of rumen simulation technique (Rusitec) vessels following removal of the fumarate treatment ${ }^{*} \dagger$ (Mean values for four vessels, with the standard error of difference between means)

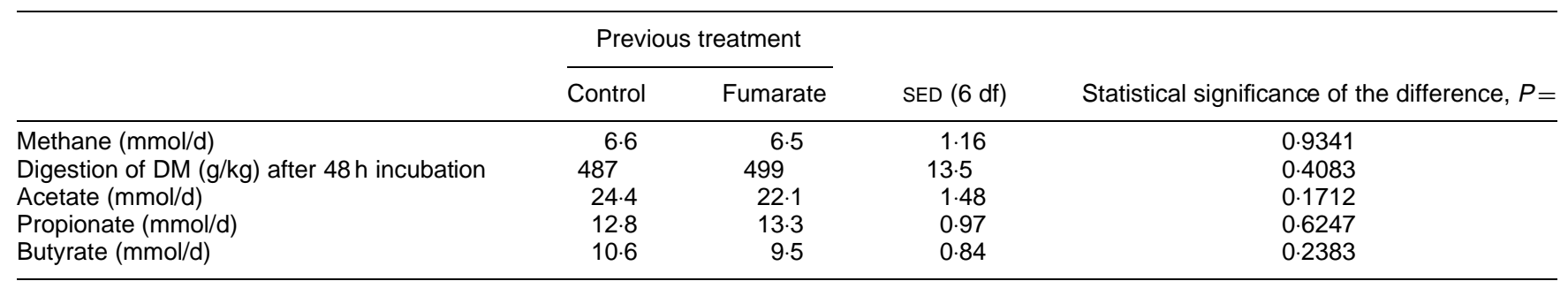

* For details of procedures, see pp. 60-61.

† Sodium fumarate had been added to Rusitec vessels for $19 \mathrm{~d}$, and each value is the mean of the observations taken over days $6-7$ after withdrawal of the fumarate treatment. 
well be different with different diets (García-López et al. 1996), and indeed the $\mathrm{pH}$ of rumen fluid can have a major influence on $\mathrm{CH}_{4}$ production (Van Kessel \& Russell, 1996). Here, the $\mathrm{pH}$ was much higher than the critical value of 6.0 enabling maximal $\mathrm{CH}_{4}$ formation (Van Kessel \& Russell, 1996).

The decrease in $\mathrm{CH}_{4}$ production observed in batch cultures was very low considering the amounts of fumarate added, and appeared to increase only slightly when the dose was increased from 250 to $500 \mu \mathrm{mol}$ per incubation. Fumarate was a more effective alternative hydrogen sink to $\mathrm{CH}_{4}$ in the Rusitec compared with batch cultures. Based on the equation $4 \mathrm{H}_{2}+\mathrm{CO}_{2}=\mathrm{CH}_{4}+2 \mathrm{H}_{2} \mathrm{O}$ and the reduction of fumarate to succinate by $2 \mathrm{H}$, in the Rusitec $6.25 \mathrm{mmol}$ fumarate caused a $1.2 \mathrm{mmol}$ fall in $\mathrm{CH}_{4}$, equivalent to an efficiency of hydrogen trapping of $1.2 \times 4 / 6.25=77 \%$, indicating that this organic acid may act as an effective hydrogen sink, competing with methanogenesis. But the inhibition achieved was still only $17 \%$, and thus fumarate would be impractical as a means of eliminating $\mathrm{CH}_{4}$ emissions in vivo. The fumarate concentrations were indeed high, selected to be similar to the anticipated $\mathrm{CH}_{4}$ production, so that the maximum potential of fumarate to divert $\mathrm{H}_{2}$ away from $\mathrm{CH}_{4}$ could be explored. It emerged that the limit was quite low, presumably because of the much lower affinity of fumarate reductase for $\mathrm{H}_{2}$ than hydrogenase of methanogenic archaea.

There may be other beneficial effects of fumarate, however. During fermentation in the Rusitec, fumarate stimulated the numbers of cellulolytic bacteria threefold. The reason for this increase is not clear. Although it has been demonstrated that cellulolytic organisms benefit from the presence of methanogenic or other $\mathrm{H}_{2}$-utilizing bacteria because of interspecies $\mathrm{H}_{2}$ transfer (Wolin \& Miller, 1988), $\mathrm{H}_{2}$ accumulation was not affected by fumarate in the Rusitec. Nevertheless, an increased DM digestibility was observed in the Rusitec trial, consistent with the increased numbers of cellulolytic bacteria, indicating that one of the beneficial effects of fumarate may be to increase fibre digestion.

Fumarate and other dicarboxylic acids also promote lactate utilization by the predominant ruminal anaerobe $S$. ruminantium (Nisbet \& Martin, 1990), stimulating its growth in vitro (Nisbet \& Martin, 1993). Improved removal of lactate may help to prevent acidosis, and would indirectly stimulate fibre digestion. However, lactate concentrations in the Rusitec were very low, and $\mathrm{pH}$ was stable, so this effect would be of minimal importance in the present experiment. The addition of fumarate also resulted in a significant increase in total gas production in batch cultures, which has to be attributed to increased $\mathrm{CO}_{2}$ production, as there was no effect on $\mathrm{H}_{2}$ production and $\mathrm{CH}_{4}$ was decreased. The increase in $\mathrm{CO}_{2}$ production may act together with the removal of lactate to buffer ruminal fermentation.

Redirecting the hydrogen produced during rumen fermentation caused changes in the outputs of other metabolic intermediates and end-products. The response to the daily addition of $6.25 \mathrm{mmol}$ fumaric acid to the Rusitec vessels was a decrease in $\mathrm{CH}_{4}$ production of $1.2 \mathrm{mmol}$ (equivalent to the consumption of $4.8 \mathrm{mmol} \mathrm{H}_{2}$ ) and an increase in propionate production of $4.9 \mathrm{mmol}$. Thus, the decrease in $\mathrm{CH}_{4}$ corresponded well to the fraction of the fumarate that was converted to propionate. The conversion via succinate, and thereafter to propionate, was the way by which most ( $89 \%)$ of the added fumarate was fermented in the Rusitec. Most of the fumarate was recovered as propionate and a small part as succinate, which accumulated before being converted into propionate. The recoveries of fumarate as propionate in the batch cultures were $85 \%$ and $79 \%$ for the 5 and $10 \mathrm{mmol} / \mathrm{l}$ additions respectively, which is in reasonable agreement with results observed in the Rusitec. However, $\mathrm{H}$ recoveries in the Rusitec (calculated from $2 \mathrm{H}$ produced $=2 \mathrm{~A}+\mathrm{P}+4 \mathrm{~B}+3 \mathrm{~V}, 2 \mathrm{H}$ recovered $=2 \mathrm{P}+2 \mathrm{~B}+$ $4 \mathrm{~V}+4 \mathrm{CH}_{4}+\mathrm{H}_{2}$, where $\mathrm{A}$ is acetate, $\mathrm{P}$ is propionate, $\mathrm{B}$ is butyrate and V is valerate; Marty \& Demeyer, 1973) were lower (74 and $72 \%$ for the control and fumarate treatments respectively) than those recorded in the batch cultures (92$98 \%$ ). This inconsistency may indicate that some reduced end-products were missing from the analysis or that alternative pathways may have been operative, possibly direct utilization of $\mathrm{O}_{2}$ (Demeyer et al. 1972), resulting from the higher rate of $\mathrm{O}_{2}$ leakage in the Rusitec (Hillman et al. 1985). It will be important to confirm the effects of fumarate on ruminal stoichiometry in vivo.

Organic acids, and fumarate in particular, can be converted into propionate and acetate following different pathways (Demeyer \& Henderickx, 1967). Increases in acetate were observed in batch and semi-continuous cultures, although the increase in acetate production was not significant in the Rusitec. Other additives give rise to increases in propionate at the expense of acetate.

Little information is available on the effects of fumarate on ruminal digestion and animal performance in vivo. Isobe \& Shibata (1993) observed that ruminal fermentation in goats was enhanced by the addition of fumarate, increasing cellulose digestion, which is in agreement with our results in the Rusitec. There is also evidence that other dicarboxylic acids such as malate may improve animal performance in dairy (Kung et al. 1982) and beef cattle (Sanson \& Stallcup, 1984; Streeter et al. 1994). The results of the present study suggest that dietary fumarate would have a beneficial effect via decreased methanogenesis, increased propionate production and stimulation of fibre breakdown by rumen microorganisms.

\section{Acknowledgements}

S. López was supported by a fellowship under the OECD Project on Biological Resources Management. C. Valdés was supported by a fellowship of the DGICYT of the Spanish Ministry of Education and Science. Financial support by the collaborative research project 'Acción Integrada HB1996-0150' is also gratefully appreciated. The Rowett Research Institute is funded by The Scottish Office Agriculture Environment and Fisheries Department. We thank Freda McIntosh for skilled technical assistance.

\section{References}

Bryant MP (1972) Commentary on the Hungate technique for culture of anaerobic bacteria. American Journal of Clinical Nutrition 25, 1324-1328.

Callaway TR \& Martin SA (1996) Effects of organic acid and monensin treatment on in vitro mixed ruminal micro-organisms 
fermentation of cracked corn. Journal of Animal Science 74, 1982-1989.

Coleman GS (1987) Rumen entodiniomorphid protozoa. In In Vitro Methods for Parasite Cultivation, pp. 29-51 [AER Taylor and JR Baker, editors]. London: Academic Press.

Czerkawski JW \& Breckenridge G (1977) Design and development of a long term rumen simulation technique (Rusitec). British Journal of Nutrition 38, 371-384.

Demeyer DI \& Henderickx HK (1967) Competitive inhibition of in vitro methane production by mixed rumen bacteria. Archives Internationals de Physiologie et de Biochimie 75, 157-159.

Demeyer DI, Van Nevel CJ \& Henderson C (1972) Stoichiometry of oxygen utilization by rumen contents. In Proceedings of the 2nd World Congress on Animal Feeding, vol. 5, part 2, pp. 3337 [International Veterinary Association for Animal Production, editors]. Madrid: Industrias Gráficas España.

García-López PM, Kung L \& Odom JM (1996) In vitro inhibition of microbial methane production by 9,10-anthraquinone. Journal of Animal Science 74, 2276-2284.

Hillman K, Lloyd D \& Williams AG (1985) Continuous monitoring of fermentation gases in an artificial rumen system (Rusitec) using a membrane-inlet probe on a portable quadrupole mass spectrometer. In Gas Enzymology, pp. 201-206 [D Degn, editor]. Dordrecht: Reidel Publishing Company.

Hobson PN (1969) Rumen bacteria. Methods in Microbiology 3B, $133-159$.

Hungate RE (1969) A roll tube method for cultivation of strict anaerobes. Methods in Microbiology 3B, 117-132.

Isobe Y \& Shibata F (1993) Rumen fermentation in goats administered fumaric acid. Animal Science and Technology 64, 1024-1030.

Kung L, Huber JT, Krummrey JD, Allison L \& Cook RM (1982) Influence of adding malic acid to dairy cattle rations on milk production, rumen volatile acids, digestibility, and nitrogen utilization. Journal of Dairy Science 65, 1170-1174.

McDougall EI (1948) Studies on ruminal saliva. 1. The composition and output of sheep's saliva. Biochemical Journal 43, 99-109.

Mann SO (1968) An improved method for determining cellulolytic activity in anaerobic bacteria. Journal of Applied Bacteriology 31, 241-244.

Martin SA \& Park CM (1996) Effect of extracellular hydrogen on organic acid utilization by the ruminal bacterium Selenomonas ruminantium. Current Microbiology 32, 327-331.

Marty RJ \& Demeyer DI (1973) The effect of inhibitors of methane production on fermentation pattern and stoichiometry in vitro using rumen contents from sheep given molasses. British Journal of Nutrition 30, 369-376.
Morvan B, Doré J, Rieu-Lesme F, Foucat L, Fonty G \& Gouet P (1994) Establishment of hydrogen-utilizing bacteria in the rumen of the newborn lamb. FEMS Microbiology Letters 117, 249-256.

Moss AR (1993) Methane Global Warming and Production by Animals. Canterbury: Chalcombe Publications.

Newbold CJ, Wallace RJ \& McIntosh FM (1997) Mode of action of the yeast Saccharomyces cerevisiae as a feed additive for ruminants. British Journal of Nutrition 76, 249-261.

Newbold CJ, Williams AG \& Chamberlain DG (1987) The in vitro metabolism of D,L-lactic acid by rumen microorganisms. Journal of the Science of Food and Agriculture 38, 9-19.

Nisbet DJ \& Martin SA (1990) Effect of dicarboxylic acids and Aspergillus oryzae fermentation extract on lactate uptake by the ruminal bacterium Selenomonas ruminantium. Applied and Environmental Microbiology 56, 3515-3518.

Nisbet DJ \& Martin SA (1993) Effects of fumarate, L-malate, and an Aspergillus oryzae fermentation extract on D-lactate utilization by the ruminal bacterium Selenomonas ruminantium. Current Microbiology 26, 133-136.

Richardson AJ, Calder AG, Stewart CS \& Smith A (1989) Simultaneous determination of volatile and non-volatile fatty acidic fermentation products of anaerobes by capillary gas chromatography. Letters in Applied Microbiology 9, 5-8.

Sanson DW \& Stallcup OT (1984) Growth response and serum constituents of Holstein bulls fed malic acid. Nutrition Reports International 30, 1261-1267.

SAS Institute Inc. (1989) SAS/STAT ${ }^{\circledR}$ User's Guide, version 6, 4th ed. Cary, NC: SAS Institute Inc.

Steel RGD \& Torrie JH (1980) Principles and Procedures of Statistics, 2nd ed. London: McGraw-Hill.

Stewart CS \& Duncan SH (1985) The effect of avoparcin on cellulolytic bacteria of the ovine rumen. Journal of General Microbiology 131, 427-435.

Streeter MN, Nisbet DJ, Martin SA \& Williams SE (1994) Effect of malate on ruminal metabolism and performance of steers fed a high concentrate diet. Journal of Animal Science 72, Suppl. 1, 384 Abstr.

Van Kessel JAS \& Russell JB (1996) The effect of pH on ruminal methanogenesis. FEMS Microbiology Ecology 20, 205-210.

Van Nevel CJ \& Demeyer DI (1996) Control of rumen methanogenesis. Environmental Monitoring and Assessment 42, 73-97.

Weatherburn MW (1967) Phenol-hypochlorite reaction for determination of ammonia. Analytical Chemistry 39, 971-974.

Wolin MJ \& Miller TL (1988) Microbe-microbe interactions. In The Rumen Microbial Ecosystem, pp. 343-359 [PN Hobson, editor]. London: Elsevier Applied Science. 